\title{
Materials for Energy Applications
}

In this issue, we present invited papers on the topic of Materials for Energy Applications. Here we have focused on two classes of energy applications, namely, materials in nuclear and materials in fossil fuel applications.

Drs. M.G. Burke and M.A. Burke of the Westinghouse Materials Center of Excellence have selected and acted as Editors for the nuclear materials group of papers and Prof. S. Sridhar of Carnegie Mellon University has acted as Editor for the papers on materials used in fossil fuel energy conversion. Each has introduced their respective selection of papers.

This is a good opportunity to solicit more papers on materials for energy conversion. Over the past few years we have had many papers on materials for energy applications; for example, we have had papers dealing with solar energy, solid oxides fuels and nuclear materials. These will now be indexed under their own category: Materials for Energy Applications. In addition, we will be having special issues of Metallurgical and Materials Transactions (in addition to our usual 13 issues of MMTA and 6 of MMTB) over the next few years which will be dedicated to papers on this topic. Dr. K. Scott Weil, Staff Scientist at Pacific Northwest National Lab, will be acting as the Editor of these special issues and we have already gathered a group of interested scientists and engineers to be Key Readers for these topics. Papers on topics like batteries, fuel cells, solar, geothermal, etc. are all potential topics, so anyone working in these fields should feel free to submit papers to us. Of course, our special niche as a journal is the role of microstructure in determining the properties of materials, and this will be an important topic of the papers dealing with these materials for energy applications.

We look forward to your submissions on topics related to Materials for Energy Applications.

David E. Laughlin Principal Editor 